Journal of Al Azhar University Engineering Sector

Vol. 13, No. 48, July 2018, 1074-1088

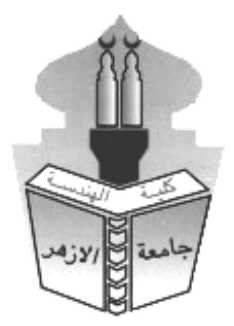

\title{
ISLAMIC GEOMETRIC PATTERNS AS TIMELESS ARCHITECTURE
}

\author{
Hesham Sobh ${ }^{1}$, Heba Allah Samy ${ }^{2}$ \\ ${ }^{1}$ Architecture, Faculty of Architectural Engineering, Al-Azhar University, Cairo, Egypt \\ ${ }^{2}$ Young Researcher of Architecture, Architect at General Authority for Educational Buildings
}

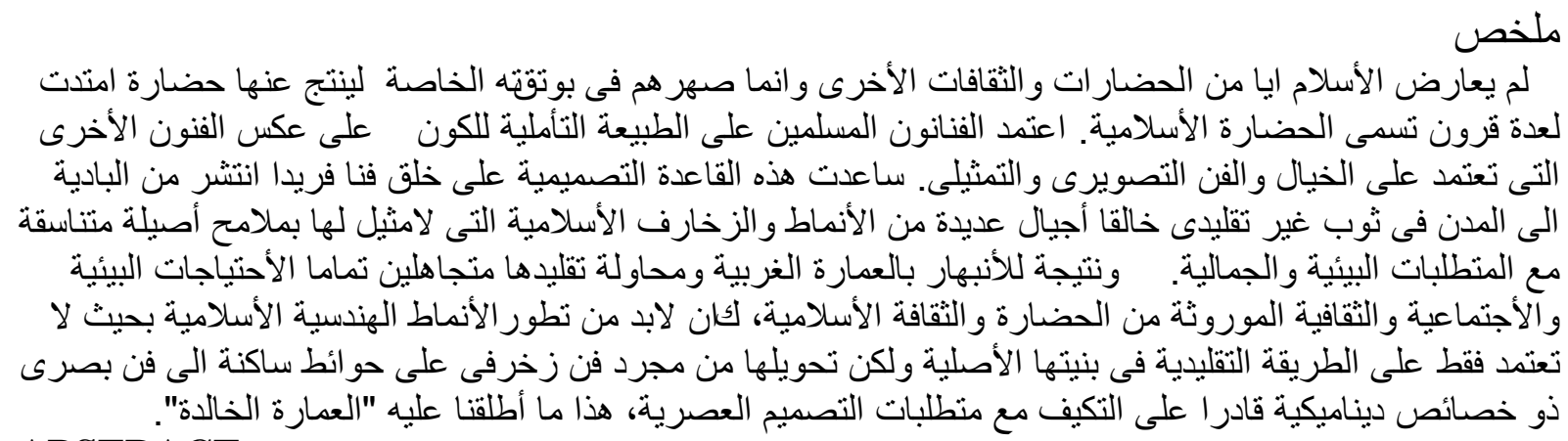

ABSTRACT

Muslim architects depend on Meditation, thinking and then results in their culture and civilization which create a unique art and architecture, instead of other artists which depend on personal perception and imagination in their cathedrals and churches designs that make the difference of Islamic art rather than other visual arts. Consequently, there was no need in the mosque for apses, transepts, crypts as well as images and sculptures that played a prominent part in the diversity of Islamic geometric patterns. This designing principle, presented a new methodology for understanding and constructing complicated Islamic patterns, which generated a new perspective into the history, craft, construction and creativity of the Muslim artists. This paper aims to present the characteristics of geometrical patterns as a digital method and point out the possibilities of mathematics of patterns which can be used to generate new depictions and applied in new areas like structure system, kinetic envelope or generate an evolution construction building on the architecture level which called "Timeless architecture."

Keywords: genetic algorithms, parametric design, timeless architecture, digital method.

\section{INTRODUCTION}

Islamic art is the expression of a whole culture, intimately intertwined with religious, theological, legal commitments and science. It is a way of expressing and celebrating the defining ideology of a community. It is always social and traditional, never idiosyncratic or wholly self-expressive.

The rise of Islamic culture in the seventh century has marked the beginning of a new artistic, decorative and sacred tradition through completely inspired by a deep religious philosophical and cosmological approach, which embodied all aspects of life and manifested itself in every product. The use of geometric patterns is one of the chief characteristics that give the Islamic artistic heritage its distinct identity. For more than thirteen centuries they acted as unifying factors. They have linked the architectural products from all over the Islamic world, extending across Europe, Africa and Asia. Most of the fields of Islamic art are linked from China to Spain by a unifying concept of composition despite, the diversity of materials, forms or styles used. 
Geometry as an abstract art form and the act of designing and applying these patterns was considered encapsulated visually diverse formations grow out from the same spiritual origin to represent the multiple manifestation of the divine.

The thesis interested in geometric patterns in terms ability for development, generation, innovation and transformation of structure origins. It will show that IGP was developed and employed with design techniques to be adapted in our time and needs and transformation our culture of geometric patterns to structure system which can use in many fields of our day.

2. The Concept of Islamic geometric patterns

The concept of geometric patterns is based on the number1 and its generation in the world, where geometric patterns and shapes abound. As number, the concept is based on symmetry, the correspondence in size, shape and relative position of parts in the whole as bilateral symmetry. In this way, the concept relates to the cosmic processes characterized by extension in all directions, by boundlessness, and by infinite to divisibility (Fig. 1).

The triangle, the square, and the hexagon patterns generate a system of closed forms of infinite numbers or develops through the complement of the original free forms, generate combinations of new possibilities, yet with the same structure origin. The qualitative essences of all basic geometric shapes aspire to a central purpose. It is out growths of the harmonious lines which particular shapes generate that differentiated patterns develop. As the surface patterns generate infinite patterns, they combine space and time in endlessly repeated patterns (Ardalan, \& Bakhtiar, 1973).

A)

B)
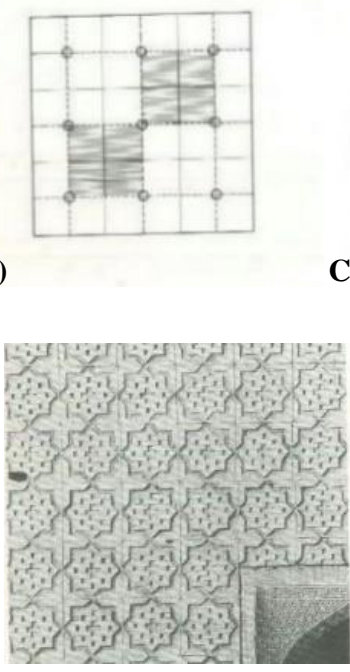

C)
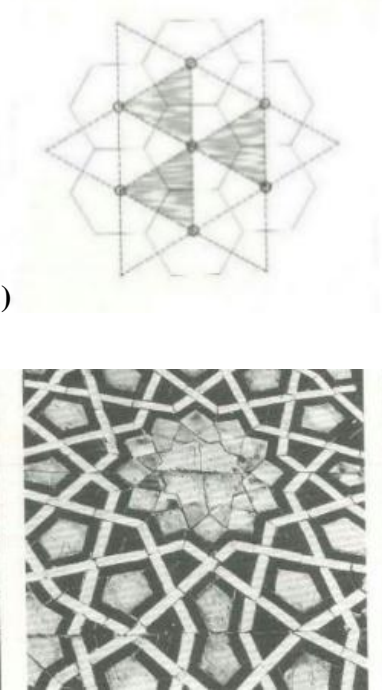

D)
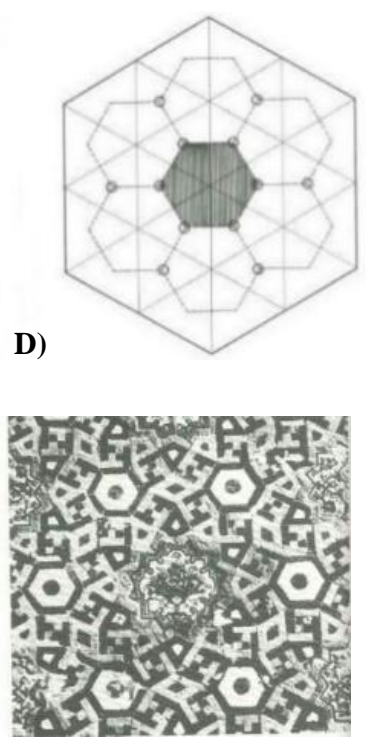

Figure 1 Complementary Space filling patterns

A. Basic shapes; square, triangle and hexagon

B. Mashhad, Masjid-I-Gawher, tile decoration

C. Isfahan, Madrasah-vl-Madar Shah, tile decoration

D. Varamin, Masjid-I-Jami, tile decoration (Source; Ardalan, \& Bakhtiar, 1973)

These shows that mathematics is the key to understand harmony and beauty. This concept can reach us to a pattern recognition process that can turn geometry to numbers and turn numbers to geometry based on the artistic relationship between geometry and numbers. This system can also perform the inverted process that is turning a certain geometrical style to a collection of shapes and forms.

\section{A NEW APPROACH TO ISLAMIC GEOMETRICAL ART}

Islamic Architecture has three basic relationships: geometric science, aesthetics and beauty phenomena, and genetic algorithms as a developed branch of mathematics and computer science (Fig. 2). 


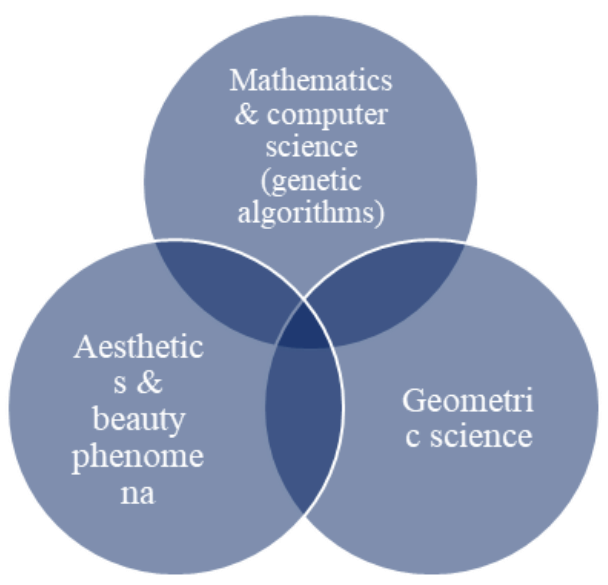

Figure 6 Relation between geometry, aesthetic and genetic algorithms (Source; By the researcher)

With the expansion of Islam, Islamic geometric patterns appeared in the buildings throughout Europe, Africa and Asia through two-dimensional (mosaic), patterns on flat and curved surfaces and three-dimensional structures (muqarnas; Gonzalez, 2001).

As the aesthetics of Islamic art is formed based on the multiplicity in unity and unity in multiplicity which implies unity. The circle, as a symbol of the universe, whose center is the creator of the world, is the central figure of decorating (in Islamic tilling, Shamseh is a crystallization of the aesthetic of this feature). A circular shape directs the viewer's look from scattering to a single point: its centers. A major evolution in geometry science happened by using parameters and genetic algorithms which begin discovering limitless generations of Islamic patterns and provide flexibility and systematization in the design process, such as tessellations. Algorithms, mathematics and art are interrelated in an art form called "algorithmic art". Algorithmic art is a visual art generated by algorithms that completely describe creation of images (Elrawi, 2014). This kind of art is strongly related with contemporary computer technology, and especially computer programming, as well as with mathematics used in algorithms for image generation.

\section{TIMELESS AS CHARACTERISTIC OF VISUAL ISLAMIC ART}

"There is a certain concern for history but it's not very deep. I understand that time has changed, we have evolved. But I don't want to forget the beginning. A lasting architecture has to have roots." Pei, 2008

Pottmann and Asperl have been invited a new definition of geometry as it is the core of the architectural design process. They studied the modern constructive geometry providing a variety of tools for the efficient design, analysis, and manufacture of complex shapes. Also, they have included many central concepts on free-form curves and surfaces, differential geometry, kinematic geometry, mesh processing, digital reconstruction, and optimization of shapes for emerging at the border between applied geometry and architecture which called industrial design (Pottmann, 2007). In this investigation, Islamic geometric patterns will express according to the family tree of Islamic geometric pattern as Broug categorized most of them and then obtained the relationship between Islamic geometry and parametric designing geometry to produce generation of transformative Islamic patterns in dynamic and timeless architecture (Fig. 3). 


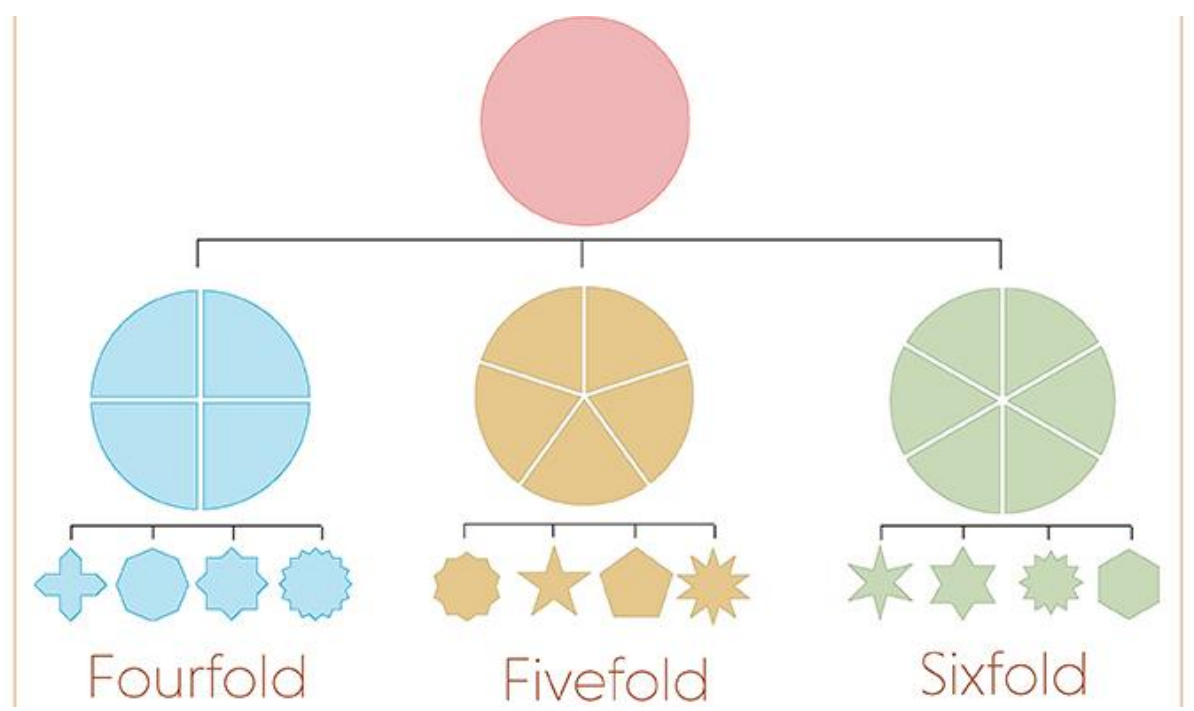

Figure 3 The family tree based on the division of a circle into four, five and six equal parts, most of IGPs can be categorized to three families: fourfold, fivefold and sixfold (Source; Broug, 2013)

The universality and timeless approach to Islamic art sees all the arts produced by Muslims everywhere as reflecting the universal verities of Islam and encompasses the infinite diversity of God creation.

Ardalan and Bakhtiar stated that geometric designs can be interpreted as abstraction of natural forms that are eternal and timeless (Ardalan, 1973; Fig. 4).

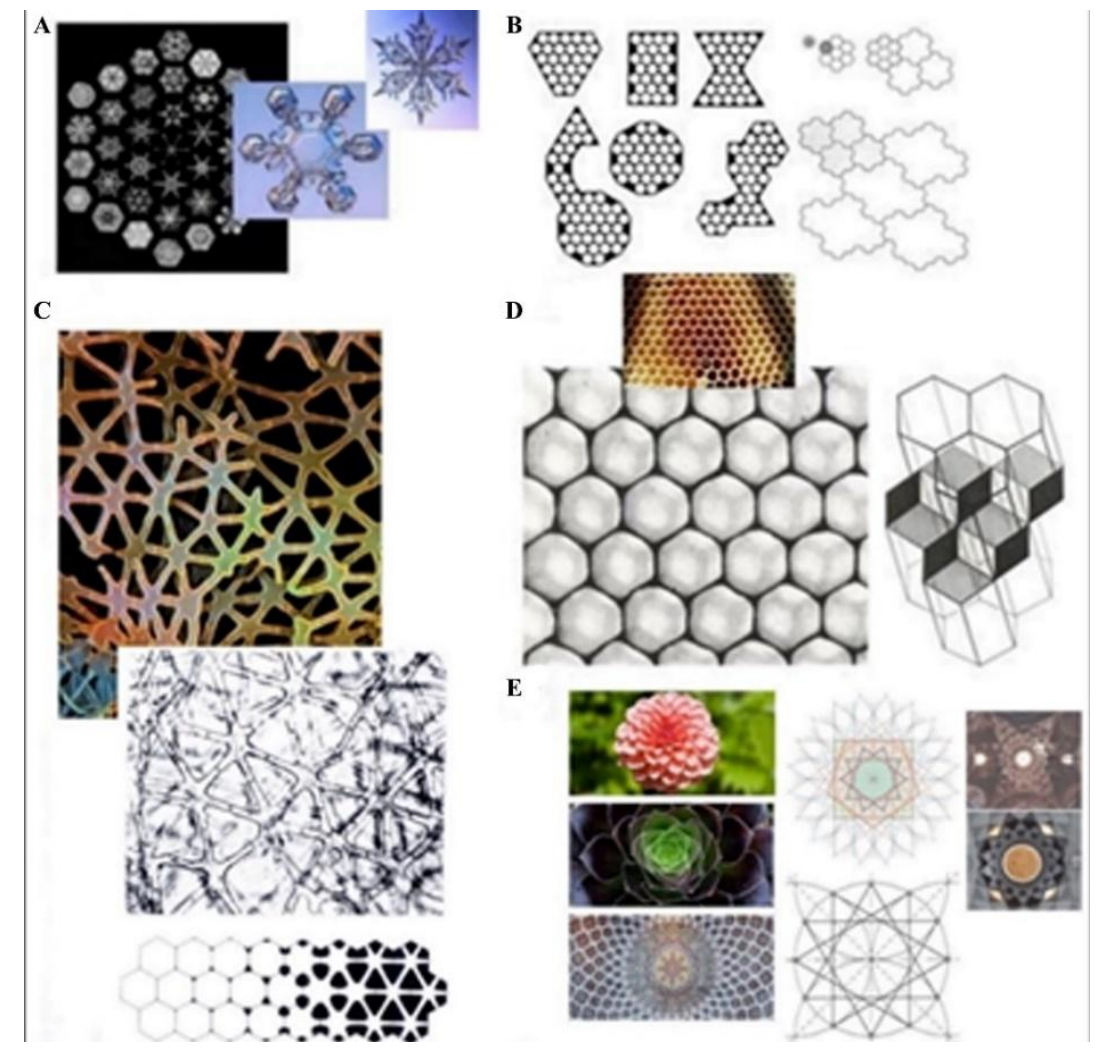

Figure 4 Geometric patterns derived from natural forms; A) Chemical, geometrical and physical interactions of snowflakes, B) A diagram of internal and external forces, C) Natural fitness and adaptation of honeycomb cell structure, D) Formation of stellate cells, E) Natural growth and development, (Source; the researcher adapted to Pearce, 1979) 
In the studying of Islamic architecture, in its playing role in the Islamic message and the identity of Islamic culture and civilization, needs to be both traditional and modern, local and university (Nasr, 2002).

That is to say, Islamic architecture in general should reflect the environmental, cultural, technological, economic, social and historical context in which it has been planted, and therefore, Islamic geometric patterns which consider the link between architecture and mathematics science. Also, reminiscent of Islamic civilization's success in creating a new culture which embraced and synthesized the diverse cultural characteristics of the societies it conquered, modern artists continued to select, reshape, and explore new ways to create contemporary art. They drew from an accumulation of sources: prehistoric, Mesopotamian, Hellenistic, Roman, Byzantine, Islamic, Persian, Coptic, and Indian. New expressions emerged in Islamic art and architecture. At the same time, Islamic geometric, ought to be contemporary and universe as well, in the sense that it will use modern compositions, techniques, systems and places, will use traditional materials and systems in new and creative ways to be integrated with the former and adopted with two principles of "form follows function" and "complexity in simplicity," seem as an application of efficiency with its structural, serviceable and functional purpose in any country or place suitable for their designs. That is to say, Muslim artists need to challenge its designs to produce buildings that are recognizable of our contemporary forms, but with an understanding and respect for religion, history, culture and context. Unquestionably, it will take us to many questions, why being creative means that nothing from the past can be borrowed, re-interpreted and reapplied, why contemporary inventions have to look odd and unpredicted, why Islamic designs are limited to Islamic building as mosques and houses and only in Islamic world and, why we limited and besieged Islamic geometric patterns in function for surface decorations, ignoring its ability for adaptable in time and space. According to Martin, Islamic architecture of the past was always in harmony with its people, their environment and their Creator. The great mosques of Cordoba, Edirne and Shah Jahan, each used local geometry, local materials and local building methods to express in their own ways the order, harmony and unity of Islamic geometry. However, in the 20th century, the Islamic concepts of unity, harmony and continuity are often forgotten in the rush for industrial and contemporary development (Latifi, 2016; Fig. 5).

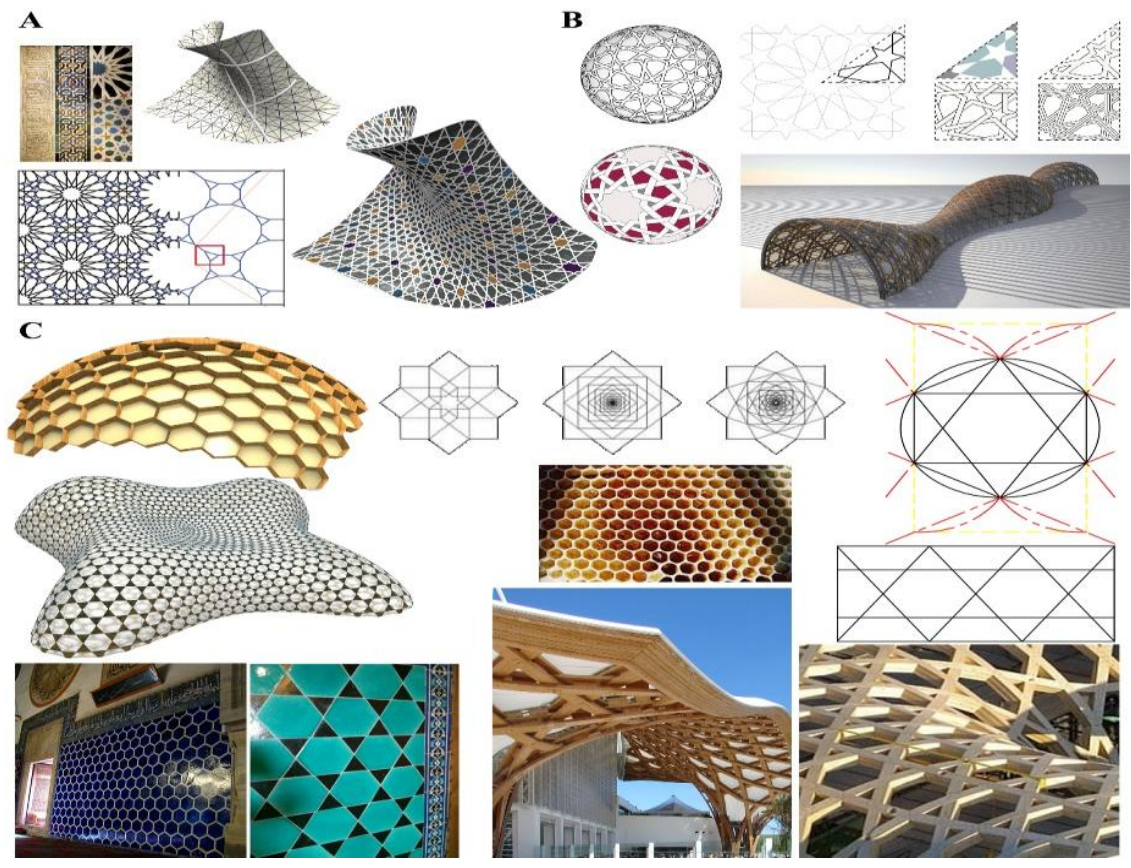

Figure 5 Many patterns transformation to structure system; A) Combination of two hexagonal webs by Transformation of an Islamic art pattern, B) Wooden production support structure by manufacturing geometric patterns on freeform surfaces, C) Honeycomb structures are defined as torsion-free support structures and polyhedral patterns (Source; the researcher adapted to Pottman, 2007, Elsaid, 1991 \& Kaplan, 2004)The best solution for Islamic architecture is to be traditional, but without just 
blindly imitating and repeating the past, and modern, albeit without rejecting tradition and constantly seeking to break with the past. Tradition and modernity in Islamic architecture must be at peace with each other.

We assumed that the understood of Islamic geometric patterns essence will allow modern building technology to be a tool in the expression of this essence. Architects and artists working today can take advantage of opportunities that new materials and mass production techniques offer. They have an opportunity to explore and transform the possibilities of the machine age for the enrichment of Islamic art in the same way that craftsmen explored the nature of geometrical and arabesque patterns.

\subsection{Why is Islamic art timeless?}

"The universe is not dualistic, but folded, so spirit is separated from matter only by degree" Laura Marks, 2010.

The cosmological nature of Islamic architecture makes it has the capacity of the adaptation, assimilation and accommodation with the development of evolutionary algorithms, parameters and their applications in architectural design.

Building upon genetic algorithms, geometric patterns have been developed a series of links between these contemporary architecture, and the algoritmicity of visual art that links new media art, computation, and various forms of Islamic art, architecture, and geometry.

Genetic algorithms are a class of highly parallel, evolutionary, adaptive search procedures. They are characterized by a string like structure equivalent to the chromosomes of nature. These represented a coded form of parameters which control the problem being investigated. Algorithm is derived from the Persian / Arabic mathematician Al-Khwarizmi and originally referred exclusively to the arithmetic rules for manipulating Arabic numbers. Nowadays, algorithm means somehow: a definite procedure for solving problems or performing tasks. An algorithm consists of instructions how to do a task by splitting it into sub-operations describing their order in a process. In most programming (or instructing) of computers it is necessary to be rigidly perfect and complete. Algorithms are rules and techniques (definite procedures) for writing such instructions or code. As Kaplan said, we have unique ability of comprehending geometric patterns, recreation, transformation and innovation, using new tools with new interpretations of old patterns (Kaplan, 2002; Fig. 6).

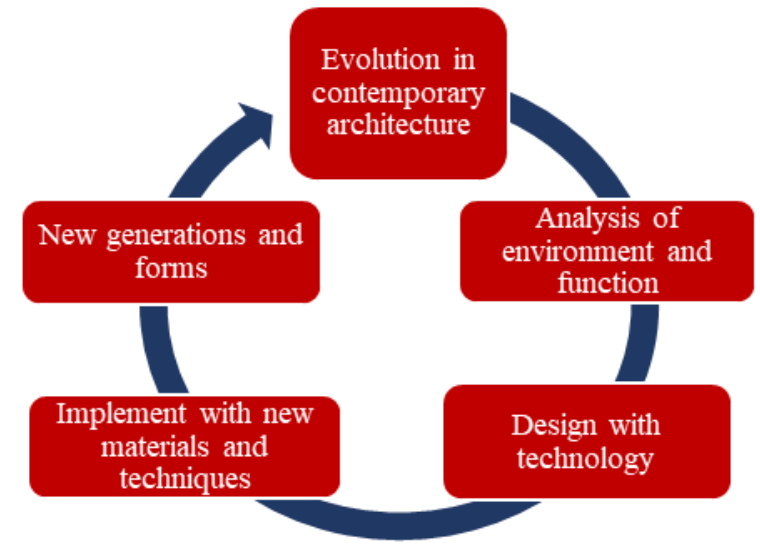

Figure 6 Genetic algorithms as a production tool maker in design process (Source; By the researcher)

While parametric design has also been widely developed for the so-called numerical and constructive approaches which converted into a system of simultaneous equations and the construction sequence of a design process (locating geometric entities through a sequence of operations, stored for further execution when parameter values are modified) (Lee and Kim, 1996). The potentials of parametric design have years of well-established application in engineering and product design (Myung and Han, 2001). In short, genetic algorithm is a programming technique, which uses genetic evolution as creating many generations of Islamic patterns and models. In contemporary architecture, speaking of different versions of Genetic Algorithms, it must be repeated and efficiently, making the importance and necessity of resorting to genetic algorithms and parametric architecture in timeless architecture.

Genetic algorithm and parameters derive its structure from the observation of nature which make Islamic visual art is a timeless art. Some structures in Islamic architecture 
when compared with some recent structures were able to develop algorithms and parameters which were able to optimize a three-dimensional pin joint space frame under the application of dynamic forces by using a genetic algorithm. The algorithm itself was based on a bottomup approach as there was no specific direction for the end topological result, but the structure was rather established on the study of its local properties. The relationship of the finite point elements called particles which compose the structure characterizes the overall outcome (Fig. 7).

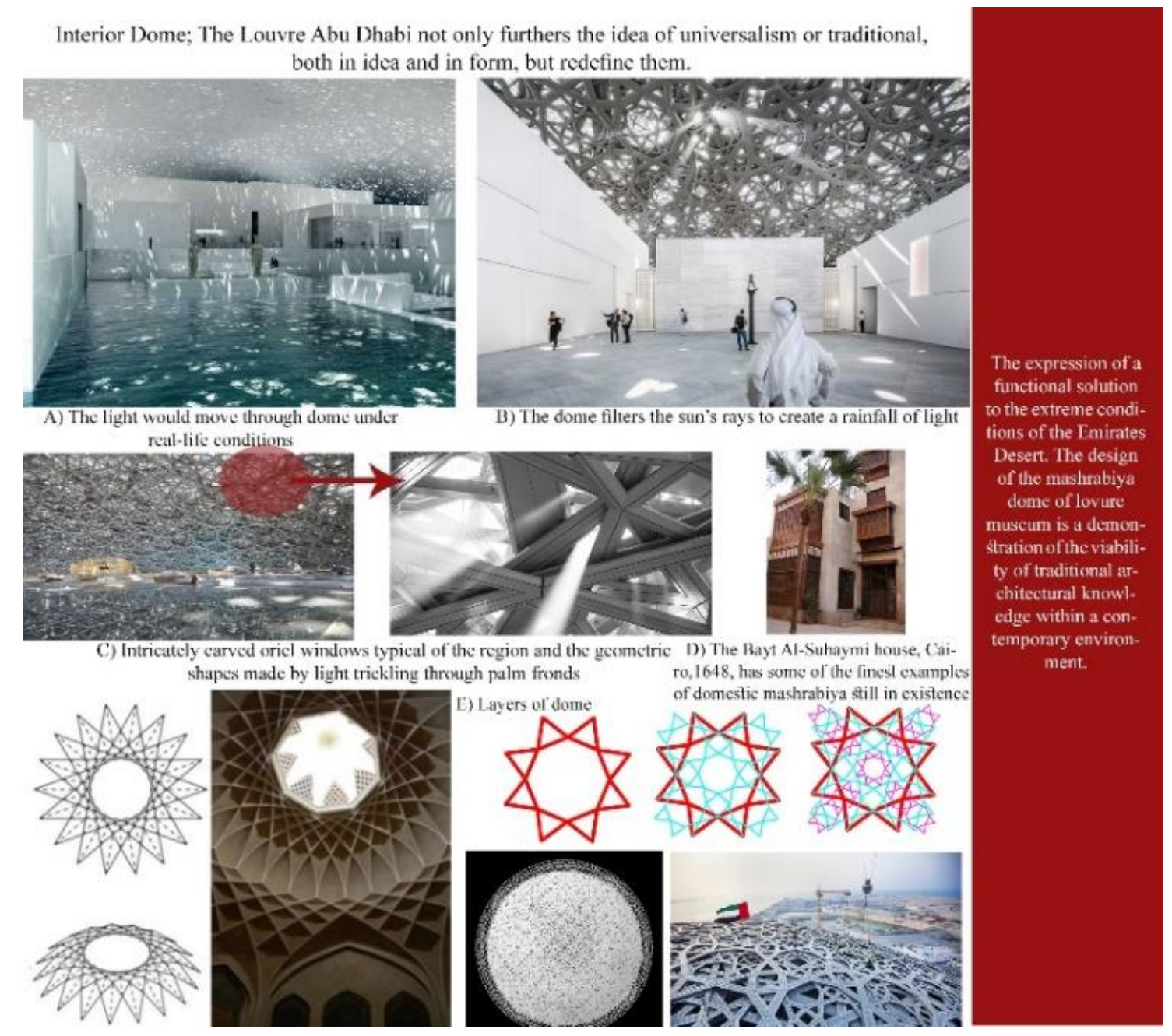

Figure 7 The adaptive system-the shape and performance react according to the whole structure (Source; the researcher adapted to http://www.france24.com \& Samuels, 2011)

When using parametric architecture various parameters including geometry and different patterns can be considered and decorative geometrical patterns parameters of Islamic domes can be expanded and developed by software. Many scholars have done work analyzing the geometry of the IGP by isolating cells and populating them to reconstruct the corresponding pattern. Recently designers have used this knowledge to create modern versions of IGP designs from scratch such is the case of Louvre Museum in Abu Dhabi as a structure case study, des0igned by Jean Nouvel that is among recent projects using Islamic patterns in designing the building envelope. This project features eight layers with a triangular pattern as floating dome structure simulating the filtering of light through the giant mantric Mashrabiya, a traditional Islamic lattice typically used to enclose second story large openings in houses and buildings (Fig. 8). The dome's geometric template of stars repeated in different sizes and at different angles in a complex arrangement forms eight distinct layers, four external and four internal. 
Case study: Louvre Museum, Abu Dhabi, United Arab of Emirates

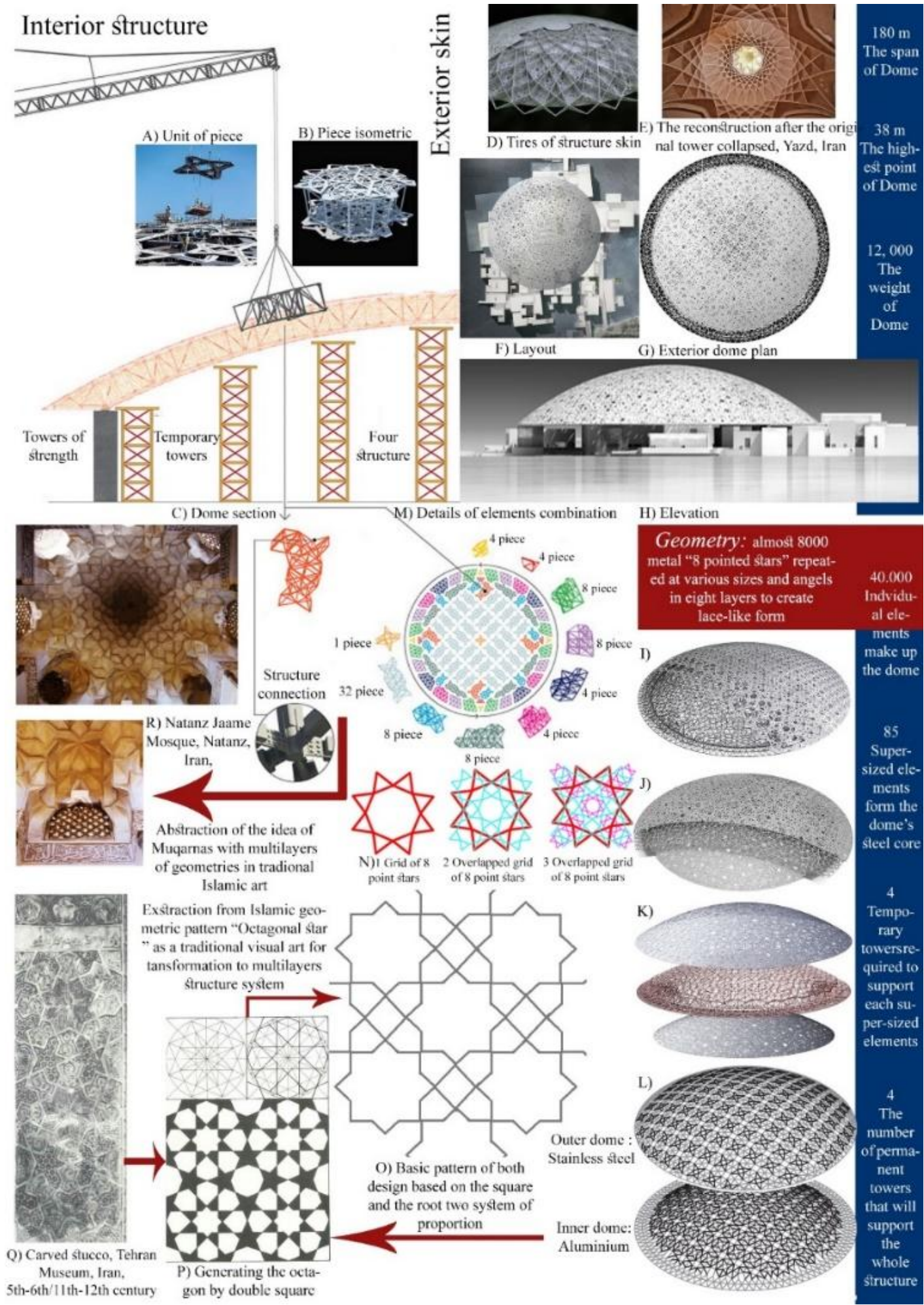

Figure 8 Parametric and genetic algorithms as abstraction tool from traditional Islamic art to structure system and adaptive building (Source; the researcher adapted to Elsaid, 1991 \& Ebrahimi, 2014)

From above, we can say that genetic algorithms are a cosmological process simulated to genetic composition of plant and human. While parametric codes of geometric patterns are visual phenomena as a result of cosmological simulation process. Both of them can explain the transformation and adaptation form in visual Islamic art from decorative to structure 
process, created many generations for reproduction and creation of timeless architecture. In other words, using parametric design patterns can be developed apparently in eliciting and interpreting formic generative algorithms of traditional Islamic patterns in creation and combination with traditional and local parameters and elements.

\subsection{How can Islamic art be timeless?}

\subsection{1 "Transformative to structure and skin"}

The thesis will prove through analytical study of the Alpha project in Qatar at nowadays by using girih tilling as a skin and structure of building with the same method in the dome of Sultan Qaitbay in the historical Cairo. The forms that would evolve from this approach would have a regional identity, a stylistic evolution, a modern appeal and a relevance to the eternal principles of Islamic visual art (Fig. 9).

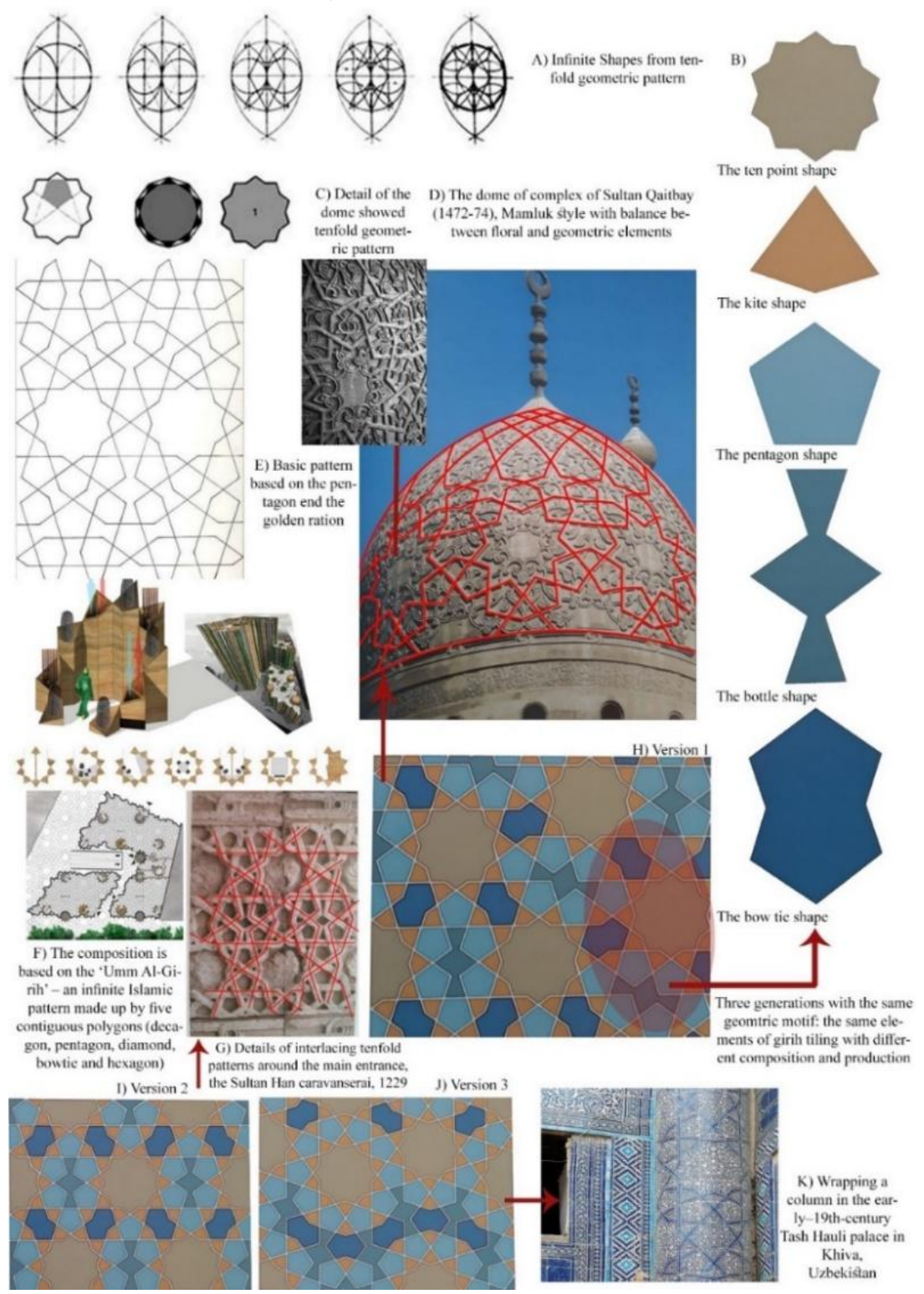

Figure 9 The main domain of transformation structure and skin, the Sultan Qaitbay in Cairo

(Source; the researcher adapted to Broug, 2013 \& Elsaid, 1991)

Geometric patterns occur in a variety of forms in Islamic art and architecture including arabesque, Persian girih and Moroccan zellige tilework, muqarnas decorative vaulting, and more. With using techniques documented by medieval Islamic mathematicians, each motif can be drawn using the direct strapwork method (El-said, and Parman, 1991). They discovered girih tiling method in 2005 used in Muslim designs for centuries. In the contemporary designs, 
architects used the basic shapes of girih tilling to challenge the past with overall free-form from function as a decoration art to skip time and place and produce three-dimensional form of architecture design modern Architecture.

Design generation requires a new definition of the concept of form. Here, the distinction between form and process, form as a static description and formation as a dynamic process becomes significant. Digitally, the designer of generated forms constructs a generative system of formal production, controls its behavior over time and selects forms that emerge from its operation (Peter, 2008). This principle of generation is a process that leads to the emergence of form and is currently driving the shift from the form making to form finding, and that was the process applied in the case study: The Alpha Project (generated structure skin with the same pattern; Fig. 10). Case study: The Alpha Project, Qatar, 2010
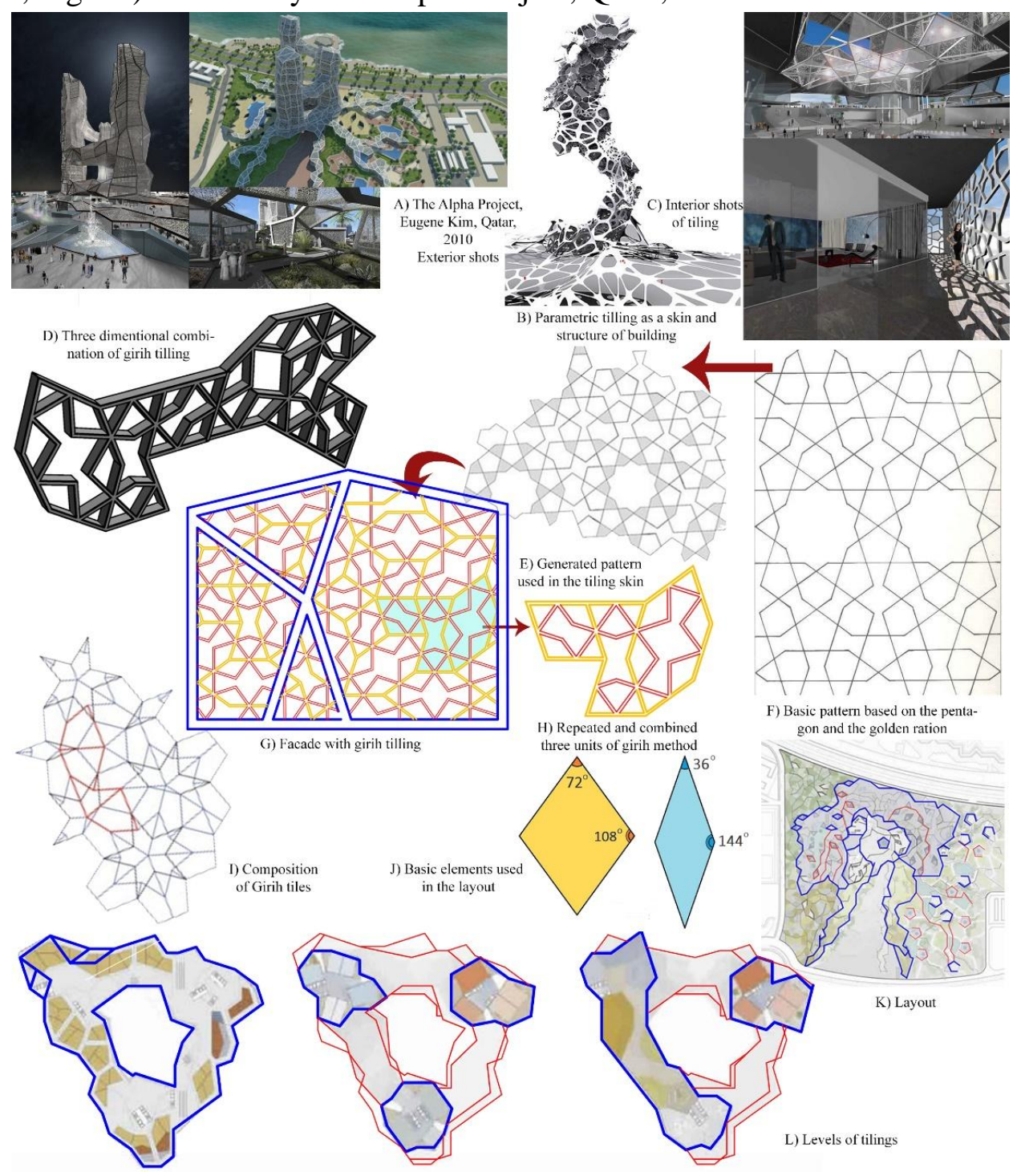

Figure 10 Formation and generation of girih tiling (Source; the researcher adapted to http://www.spacegrouparchitects.com/Projects/benetton.htm \& Elsaid, 1991)

\subsubsection{Time Fixed vs. Timeless Architecture}

The universe grows ever more so with time. Quality, superior organization and increasing sensitivity are built into the direction of the universe. Today, there is unusual mixture of science and visual languages, or design codes based on the myriad patterns of organization that the fundamental laws generate. The computer is particularly adept at revealing these patterns of nature, the fractals, strange attractors, complex morphological shapes of folding, and close packing (Elrawi, 2014). 
The fact that Islamic art was seen as purely decorative surfaces would bewilder to argue that the source of these "patterns" was indeed natural in that they explore the natural and cosmic order are also reflections of the timeless truth of unity. The principle of unity brought into being an aniconic art in which the spiritual world was reflected in the sensible world not through iconic forms, but through arabesque, muqarnas and rhythm (time). Islamic artists appropriated key elements from the classical tradition, and then elaborated upon them to invent a new form of decoration that stressed the importance of unity, logic, and order. Essential to this unique style were the contributions made by Islamic mathematicians, astronomers, and other scientists, whose ideas and technical advances are indirectly reflected in the artistic tradition.

Islamic Architecture proved to be engaged at early stages in the history of architecture to use design methodologies that designers and researchers lately turned for inspiration to nature and its morphogenetic rules in order to improve the performance of their designs and introduced this a new term for architecture. Architectural concepts were not only the representation of shapes and forms but rather a set of generative rules whose evolvement leads to the formation of space. Within the hierarchy of spatial definition, shapes are delimited by their surfaces. So, we will compare between Chrysler building in New York as belongs to post modern architecture and Header Tianjin Yujiapu Station at China, as a contemporary architecture case study (Fig. 11).

- It is clear from the comparative analysis in figure (11) that the iconic elements used in Islamic architecture compared to any architectural style in the history of architecture, has the ability of developments through up to date form generation process (digital process).

- The pediment used in Christian architecture is used as it is after 6th centuries on a top of an office building by William Van Alen, where nobody could recognize it. The design of two building was the same way even, their interior and exterior decoration. On the contrary, traditional Islamic patterns based on in stored mathematical data were developed, regenerated and reused in a completely different function and also in a homogenies compatible sense of cognition.

- The evolution of digital design thinking in the last decade now appears to have generated a new paradigm for contemporary design. If the very nature of design is radically changing and geometry constitutes a graphic description of the universe, represent how Islamic geometric patterns can be developed or applied digital process. Visual art was designed by tradition method, it belongs to digital method, so, it is traditional in its roots and digital in its adaptive and transformative structure system (Table 1,2). 
Case study: Chrysler building in New York vs Header Tianjin Yujiapu Station in China

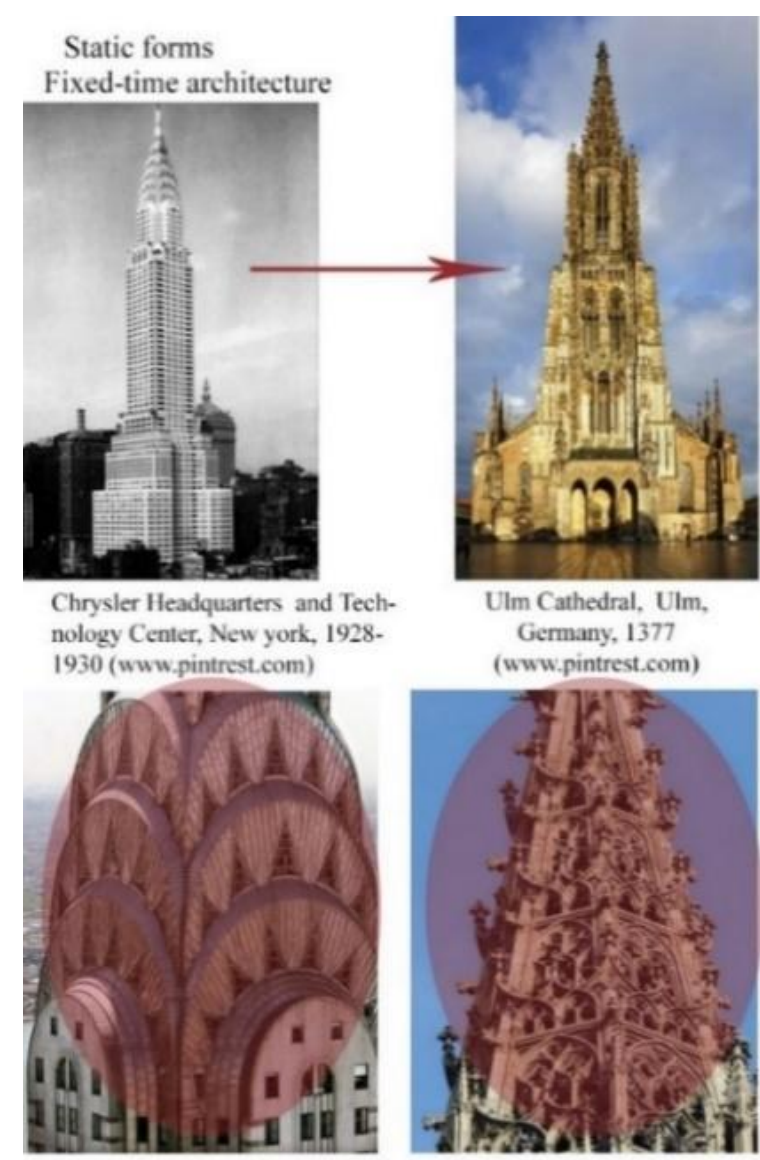

The same design and in the ending of two construction (www.pintrest.com)

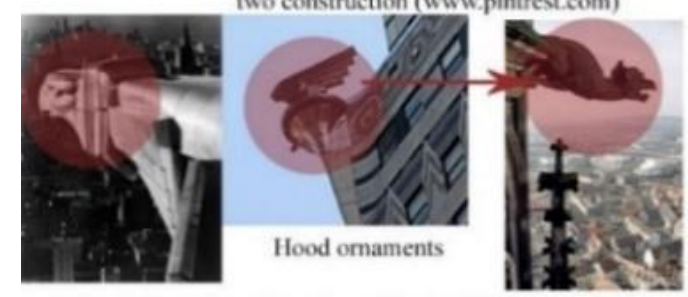

Animals figurals on the edges of two building as ornamen-

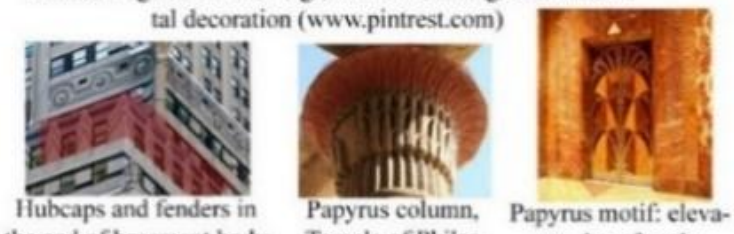
$\begin{array}{cc}\text { Papyrus column, Papyrus motif: eleva- } \\ \text { the end of basement body Temple of Philae } & \text { tor door facade }\end{array}$ (www.wikipedia.com) "Ancient Egyptian (www.wikipedia.com)

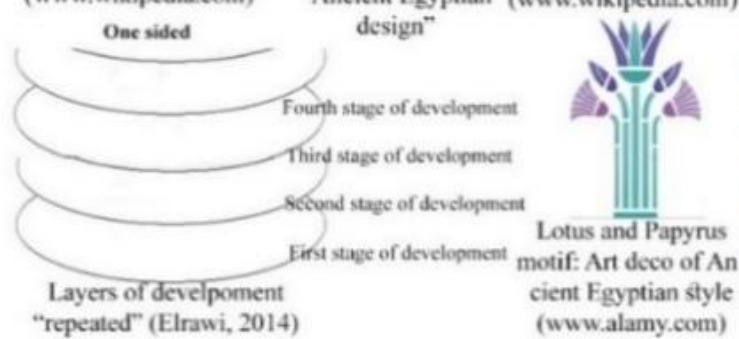

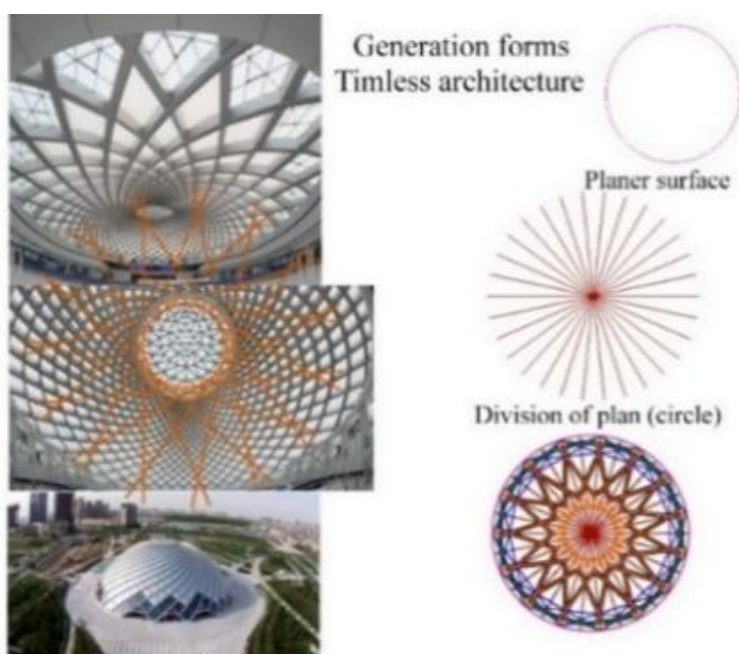

Header Tianjin Yujiapu Station China, Decorative art to structure design 2015 (http:/dimscale.blogspot.com.eg) (https:/www.semanticscholar.org

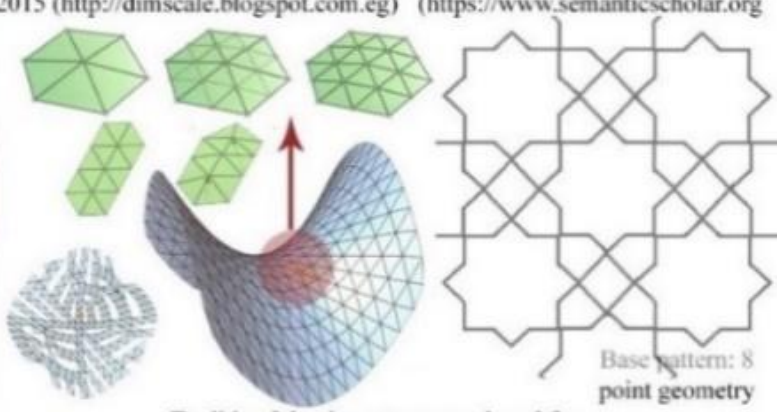

Tradition Islamic pattems employed for structure transformation

(Helmut Pottmann, 2007, architecture geometry)

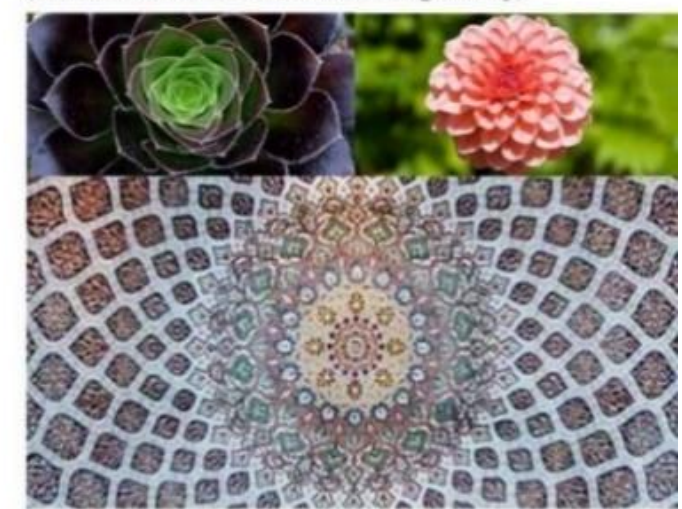

The Shah Mosque at Isfahan,

an, 1611, tiled geometric patterns

(https://www.flickr.com)

Design in both are based on four- or eight point geometry from which the spirals are derived.

Layers of development " continous" (scalapajP.j., Cad Principles for architectural design, 2001)

Figure 11 Growth and development in visual Islamic art and architecture according to the natural order (Source; the researcher adapted to Pottman, 2007 \& SzalapajP.j., 2011) 
1- Timeless architecture

Table 1 (Source; the researcher adapted to Oxman, 2006)

\section{Digital Method}

\begin{tabular}{|c|c|}
\hline Formation & $\begin{array}{l}\text { Emerging design theory has } \\
\text { transformed the concept of form into } \\
\text { the concept of formation associated } \\
\text { with topological, parametric and } \\
\text { animation. Topological design is } \\
\text { based on the exploitation of } \\
\text { topology and non-Euclidean } \\
\text { geometry. Parametric design is } \\
\text { based on principles of generative } \\
\text { components. Animation, morphing } \\
\text { and other range of motion and time- } \\
\text { based modeling techniques are } \\
\text { based on the propagation of multiple } \\
\text { discrete instantiations in a dynamic } \\
\text { continuum. }\end{array}$ \\
\hline
\end{tabular}

Generation Generative models of digital design are characterized by the provision of computational mechanisms for formalized generation processes. Here, as compared to formation models, shapes and forms are considered to be a result of preformulated generative processes.
Muslim method makes the transformation of geometric patterns from decorative art as the concept of form to structure system as formation concept with dynamic multilayers.

Doha Office Tower, Qatar, 2012

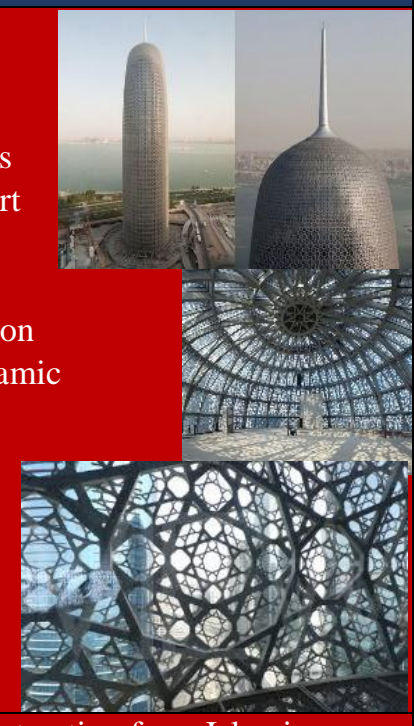

Generation and Extraction from Islamic geometric pattern "Octagonal star" as a traditional visual art for transformation to multilayers structure system.

\section{to}

\section{Performanc Performance-based models are e driven by performance and potentially integrated with formation and generative processes.}
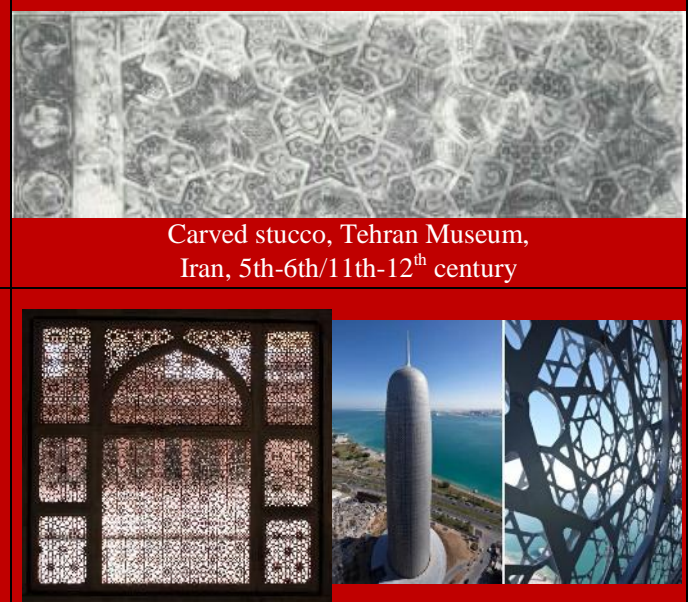

Salim Christi Tomb in Fatehpur Sikri

Abstraction of the idea of Mashrabiy with multilayers of geometries in traditional Islamic art. 
2- Transformative and adaptive structure

Table 2 (Source; the researcher adapted to Oxman, 2006)

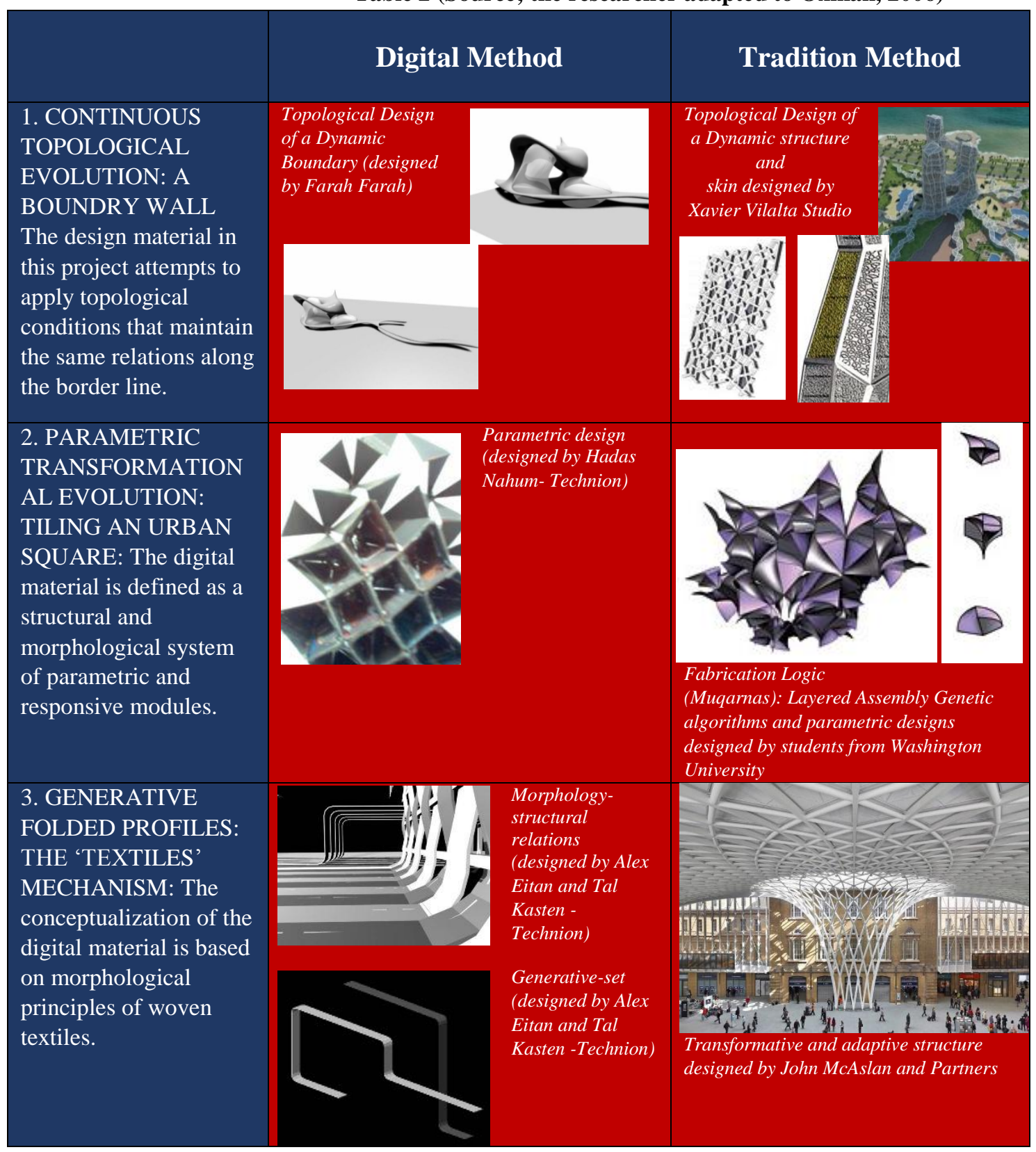

\section{CONCLUSION}

- Visual art in Islamic architecture are timeless, transformative and adaptive, it is undefined with time, human or place. The concept of visual Islamic art is the result of a comprehensive ideological system that is based on the axiom of choice and the well ordering principles of creativity and creation.

- Deep analysis for this architectural heritage, proved the use of tools and techniques of evolutionary genetic algorithms regardless using this terminology in the history of this type of architecture. The reason for that is the cosmological nature of this architecture which was ideologically oriented toward the laws of nature which God had created in his universe. The laws of nature turn out to be universal (apply everywhere in the universe), absolute (do not depend on anything else), eternal (do not change with time), omnipotent (all-powerful), and creative (Cosmo genetic). Primitive analogies are found at several levels between cosmic and human processes. In Islamic architecture, both spaces and archetypes are genetic, parametric 
and generative, to be in this manner compatible with the universe that grows in complexity and also offspring that growth in culture.

\section{REFERENCE}

1. The Holy Quran

2. Ardalan, N., and Bakhtiar, L., The Sense of Unity; The Sufi Tradition in Persian Architecture, University of Chicago Press, Chicago, 1973

3. Broug, E., Islamic geometric design, Thames \& Hudson; $1^{\text {st }}$ Edition, 2013

4. Castle, H., Oxman, R., and Oxman, R., The New Structuralism Design, Engineering and Architectural Technologies, John Wiley \& Sons Ltd, 2010

5. Critchlow, K., Islamic Patterns: An Analytical and Cosmological Approach, Schocken Books, Thames and Hudson, London, 1976

6. Gonzalez, V., Beauty and Islam: Aesthetics in Islamic Art and Architecture, I.B. Tauris Publishers, New York and London, 2001

7. Nasr, S. H., Islam: Religion, History and Civilization, Harper Collins e-books, 2002

8. Pearce, P., Structure in nature is a strategy, 3rd Edition, MIT Press, USA, 1979

9. Pottmann, H., Asperl, A., Hofer, M., and Kilian, A., Architectural Geometry, Bentley Institute Press, USA, 2007

10. Kaplan, C. S., Computer Graphics and Geometric Ornamental Design, A dissertation submitted in partial fulfillment of the requirements for the degree of $\mathrm{PhD}$, Washington University, 2002

11. Lu, P. J., and Steinhardt, P. J., Decagonal and Quasi-Crystalline Tiling in Medieval Islamic Architecture, 2007, Available at www.sciencemag.org

12. Lu, P. J., and Steinhardt, P. J., Quasicrystals: A New Class of Ordered Structures, Vol. 53, No. 26, The American Physical Society, 1984

13. Oxman, R., Theory and design in the first digital age in R.Oxman (ed), a special issue on Digital Design, Design Studies, Elsevier, Vol 27 No 3, UK, 2006

14. Oxman, R., Digital Design Thinking': in The New Design is The New Pedagogy, 2006 